\title{
Causes and Prevention of Crimes of Resisting Epidemic Prevention and Control Measures - from the Perspective of Social Conflict Theory
}

\author{
Rui Zhang \\ College for Criminal Law Science, Beijing Normal University, Beijing 100875, China \\ regard1996@163.com
}

\begin{abstract}
By studying the social conflict theories of Lewis Coser, Ralf G. Dahrendorf and Randall Collins, this paper analyzes the data distribution and specific cases of violent crimes of resisting epidemic prevention and control measures from three aspects of conflict intensity, realistic conflict and unrealistic conflict, and inter role conflict, and explores the causes of such crimes. In order to reduce and prevent the occurrence of this kind of crime, some countermeasures such as the effective sanctions, the feasible communication channels and the strengthening of civic awareness are put forward.
\end{abstract}

Keywords: Social conflict, Epidemic prevention and control measures, The intensity of conflict, The conflict of reality.

\section{Introduction}

Before 1950s, American structural functionalism regarded "conflict" as an abnormal phenomenon in the establishment of social order, and ignored it as a negative factor. Since the 1950s, Parsons' functional sociology has gradually weakened, and sociologists represented by Lewis Coser, Ralf G. Dahrendorf and Randall Collins have put forward new conflict theories under the background of the expansion of the influence of European social thoughts and the reflection of local sociology.

Based on Simmel's conflict theory, Coser's conflict theory focused on Simmel's "network of conflict" - the network of struggle and conflict under social unity. Coser basically established his sociological theoretical system around the social function and significance of conflict, so his theory was called "functional conflict theory". In the Function of Social Conflict, he developed Simmel's thought, focusing on the origin, type, result and function of conflict [1]. He believed that conflict can eliminate tension, promote group unity and prevent social fossilization, which was called positive function of conflict. Dahrendorf's contribution to conflict theory is mainly in two aspects: one is social theory, that is, the general principle of social conflict; The second is the analysis of specific conflicts in modern society. He did not completely deny the view of functionalism, which only showed the structure and process of maintaining social balance, but did not contain the forces leading to imbalance in social movements. He focused on the analysis of the two opposite scenes of society, and summed up four pairs of possible opposite conditions leading to the two scenes, so his theory was also called "dialectical conflict theory". Collins's social conflict theory closely connects the process of conflict between individuals and groups with its solution. Its basic starting point is that in all stages of human society, almost all people pursue wealth, power and privilege. Everyone in the society tends to resent being directed by others, and everyone tries to avoid being directed by others. People in the society should safeguard and seek their basic interests for their own survival [2].

Society has two sides of dialectics: static equilibrium and dynamic conflict. During the COVID-19 period, the necessary prevention and control measures adopted by various places inevitably infringe upon the freedom, property or other rights of citizens and organizations concerned. In order to preserve the overall interests of the society, the implementation of these measures have exacerbated the conflict between the public and people who carry out the epidemic prevention and control measures to some extent, which directly damages the effectiveness of the epidemic prevention and control measures. There is a significant risk of causing the spread of the epidemic.

Typical cases of obstructing COVID-19 prevention and control crime were released in February 10, 2020 from the Supreme People's court, the Supreme People's Procuratorate, and the courts and procuratorates of various localities, after the Supreme People's court, the Supreme People's Procuratorate the Ministry of public security and the Ministry of Justice issued the Opinions on punishing the crimes of obstructing novel Coronavirus infection pneumonia preventing and control according to law (Hereinafter referred to as the Opinions). According to the Opinions, crimes against epidemic prevention and control measures include the intentional spread of novel coronavirus's spreading crime and violent crimes that obstruct the staff of state organs to perform epidemic prevention and control measures according to law. The crimes against epidemic prevention and control measures described in this paper are only violent crimes. Through the study of the above social conflict theory, this paper will use the social conflict theory to analyze the data distribution characteristics and specific cases of violent crimes against epidemic prevention and control measures, and explore the causes of such crimes, so as to prevent and reduce the occurrence of such cases. 


\section{The Causes of the Crime of Resisting Epidemic Prevention and Control Measures from the Perspective of Social Conflict Theory}

Combined with the special background during the epidemic period, the citizens in the early stage were in a closed environment for a long time, and the personal psychological pressure would be magnified infinitely in a small space. The sudden reduction of social interaction made the pressure nowhere to release, resulting in a large number of bad emotions such as anxiety, nervousness and irritability. With the increase of epidemic prevention and control staff and frequent contact with citizens, it will increase the intensity of social conflict, and make citizens' resistance to power externalized more obvious. The following is to explore the causes of violent crime of resisting epidemic prevention and control measures from three aspects.

\subsection{The Existence of the Conflict between Reality and Non-Reality}

Coser thinks that social conflict is a means to achieve a certain purpose in interpersonal relationship, so he divides conflict into realistic and unrealistic conflict. In the process of individuals or groups in the pursuit of interests, in order to achieve the desired goal, the opposite parties often have a realistic conflict, which is regarded as the most effective means to achieve the goal. Once the parties find that there is no need to conflict, and there is a simpler way to achieve the goal, then the parties will avoid the realistic conflict [3]. According to the reasons of violent crime of resisting epidemic prevention and control measures, this kind of conflict can be attributed to the physiological factors of the actor. In addition to realistic conflicts, there are also nonrealistic conflicts which are different from realistic conflicts. The non-realistic conflict is generally caused by people's hostile psychology or aggressive psychology, which is different from the realistic conflict. The nonrealistic conflict is just to eliminate the self-tension and vent the dissatisfaction, while the realistic conflict is to strive for the rationality of self-interest. This kind of conflict does not have a specific goal, and the conflict itself is the goal. The goal of the conflict party is arbitrary, random and replaceable. Therefore, the reason of violent crime of resisting epidemic prevention and control measures can be attributed to psychological factors. To sum up, there are two reasons for violent crime of resisting epidemic prevention and control measures: physiological factors and psychological factors.

\subsubsection{The conflict of reality: physiological factors}

In addition to the crime of obstructing public service, the violent actions of resisting epidemic prevention and control measures may also constitute the crime of provocation, intentional homicide, crime of intentional injury and other crimes. This paper only takes the crime of obstructing public service as an example to analyze the influence of physiological and psychological factors on the violent crime of resisting epidemic prevention and control.

On the website of Chinese judgement documents, there are 231 documents with the keywords of "case type: criminal case, cause of action: Crime of obstructing public service, year of judgment: 2020, court level: grassroots court, full text: epidemic prevention and control"; With the keywords of "case type: criminal case, cause of action: Crime of obstructing public service, year of adjudication: 2020, court level: grassroots court, full text: epidemic prevention and control, female", there are 41 documents; With the keywords of "case type: criminal case, cause of action: Crime of obstructing public service, year of adjudication: 2020, court level: grassroots court, full text: epidemic prevention and control, male", there are 192 documents, and the error is less than $5 \%$.

Table 1: Search results of the proportion of gender in the crime of obstructing public service

\begin{tabular}{|c|l|l|c|c|c|c|}
\hline No. & Types of cases & Cause of action & Referee year & Court hierarchy & Full text & Number \\
\hline 1 & criminal case & Crime of obstructing public service & 2020 & Grassroots courts & Epidemic prevention and control & 231 \\
\hline 2 & criminal case & Crime of obstructing public service & 2020 & Grassroots courts & Epidemic prevention and control, women & 41 \\
\hline 3 & criminal case & Crime of obstructing public service & 2020 & Grassroots courts & Epidemic prevention and control, male & 192 \\
\hline
\end{tabular}

According to the search results, it can be known that during the epidemic period, about $18 \%$ of the perpetrators of violent crimes against the epidemic prevention and control measures were women, and about $82 \%$ were men. Men were more inclined to carry out such behaviors. There are two reasons.

One is the influence of body shape. Ernst Kretschmer in his representative work Physique and Character posited three chief constitutional groups: the tall, thin asthenic type, the more muscular athletic type, and the rotund pyknic type. People with strong physique are more likely to commit crimes against other people's personal safety [4]. Men are stronger than women, and they are more inclined to implement violent crime of resisting epidemic prevention and control measures.

The second is the special physiological structure. It is found that the secretion of testosterone is closely related to the generation of hostility, aggressive behavior and violent

behavior. Excessive testosterone secretion can cause violent and aggressive behavior. Historical studies on rape, homicide and other behaviors show that the perpetrators often show high testosterone levels. And this kind of violence often lasts for a period of time [5]. Testosterone is a kind of male hormone. The amount of testosterone secreted by adult men is much more than that of women. Therefore, during the epidemic period, especially during the implementation of closed management, male actors who want to pass through the checkpoint often think that

violence is the most effective means to achieve the goal. And through the website of Chinese judgement documents, with the keywords of "case type: criminal case, cause of action: Crime of impairing public service, year of adjudication: 2020, court level: grassroots court, full text: epidemic prevention 
and control, full text: recidivism", there are 13 documents, where the defendants are all male. This shows that men are more likely to take conflict as a means to achieve their goals, and are more likely to have multiple and long-term violent behaviors.

\subsubsection{Unrealistic conflict: psychological factors}

The external performance of the individual in violent crime is mostly impulsive behavior, which is related to the external effect of alcohol and personal negative personality. On the website of Chinese judgement documents, there are 60 documents with the keywords of "case type: criminal case, cause of action: Crime of obstructing public service, year of judgment: 2020, court level: grassroots court, full text: epidemic prevention and control, full text: drunk", accounting for $26 \%$ of the research cases. With the keywords of "case type: criminal case, cause of action: Crime of obstructing public service, year of judgement: 2020, court level: grassroots court, full text: epidemic prevention and control, full text: dissatisfaction", there are 39 documents, accounting for about $17 \%$ of the research cases.

Table 2: The influence of psychological factors on the crime of obstructing public service

\begin{tabular}{|c|c|c|c|c|c|c|}
\hline No. & Types of cases & Cause of action & Referee year & Court hierarchy & Full text & Number \\
\hline 1 & criminal case & Crime of obstructing public service & 2020 & Grassroots courts & Epidemic prevention and control, drinking & 60 \\
\hline 2 & criminal case & Crime of obstructing public service & 2020 & Grassroots courts & $\begin{array}{c}\text { Epidemic prevention and control, } \\
\text { dissatisfaction }\end{array}$ & 39 \\
\hline
\end{tabular}

Human rationality is produced in the prefrontal cortex of the brain, which is equivalent to the police or gatekeeper of the brain examining various human emotions generated by the limbic system of the brain. The final confirmed emotions will be output as external behaviors. Alcohol, as a sedative, inhibits the prefrontal cortex. Some emotions are output without examination and form external behavior. At this time, the actor's consciousness is fuzzy, the level of reason is declining, the emotion is impulsive, and violence that doesn't happen in everyday life happens after drinking. According to Freud's theory of personality structure, under the influence of alcohol, the monitoring ability of ego and superego declines, and people are more driven by the instinct of id to make some behaviors that they would not normally do.

Because of the negative personality of the individual, the perpetrator has the psychology of revenge and catharsis, thus the implementation of violence is also more common.

Case 1: at about 13:30 on February 9, 2020, the son of the defendant Zhang was asked by the security guard to suspend entering the community due to abnormal body temperature. After the second temperature measurement was normal, he was released. As a result, the defendant was dissatisfied and refused to leave the car parked at the entrance of the community. He asked the security guard to show the relevant documents that the high temperature could not enter the community, so that other cars could not pass through. After repeated warnings from the police, the defendant got on the car and slowly moved the car by braking, delaying the departure. The police then asked the defendant to get off the car, but he still refused to do that. When the police forced him to leave, the defendant suddenly accelerated away, causing the police arm to be hit by the car.

Case 2: at about 6:30 on January 31, 2020, police Fan of Xianghua police station of Chongming branch of Shanghai Public Security Bureau maintained order in Xiangzhong Road pharmacy of Xianghua town in the district. Because the pharmacy limited the sale of masks, police Fan advised the people behind to stop queuing after counting the number of people. The defendant Chen was dissatisfied and slapped police Fan in the face. After identification, Fan was injured by external force which constitutes a minor injury of facial soft tissue contusion.
People's frustration comes from their unsatisfied needs and desires. So some people will turn frustration into aggressive behavior. The degree of aggressive behavior, the intensity of desire and the degree of frustration are in direct proportion to each other. In case 1, the defendant Zhang wanted to enter the community quickly, and in case 2 , the defendant Chen wanted to buy a mask quickly. However, due to the duty behavior of the security guards and the police, their needs cannot be met, which will produce frustration such as anxiety and dissatisfaction, and then this bad mood would turn into aggressive behavior to vent their anger.

\subsection{An Increase in the Intensity of Conflict}

Coser's social conflict theory contains two basic hypotheses. The first hypothesis is about the social conditions of the increase and decrease of conflict intensity; The second is the internal and external integration function of conflict for the groups involved. As for the intensity of conflict in the first hypothesis, Coser thinks that it is the degree to which the two sides of the conflict try to harm or repel each other [6]. Obviously, Coser thinks that the intensity of the conflict mainly reflects the destructiveness of the conflict and the degree of mutual exclusion between the opposing parties [7]. However, I agree more with Dahrendorf's explanation of the intensity of conflict. He introduces the concepts of "intensity of conflict tension" and "conflict violence" to describe the intensity of conflict. The intensity of conflict tension refers to the energy consumption of various aspects of conflicts and the degree of their involvement in conflicts. Conflict violence refers to the degree of weapons and means used by conflict groups. The intensity of conflict tension is affected by a series of variables. Only by understanding these variables and controlling them effectively can the intensity of conflict tension be weakened or enhanced [8]. Through cases of violent crimes against COVID-19 prevention and control measures, there are three factors that cause the increase of social conflict intensity:

One is the popularization of conflict behavior. The nationalization of COVID-19 prevention and control measures will lead to the popularization of the conflict subjects, and a large number of potential subjects may be involved in any conflict at any time. Every epidemic prevention station of each city, district, intersection and street 
may become the factor and place of conflict behavior, which will increase the conflict intensity. It is clear in the Opinions that the criminal policy for this crime should be heavier. Therefore, many behaviors do not require causing minor injury or more, which reduces the limit of conflict behavior and popularizes it. Tearing, pushing, scratching and other behaviors may constitute this crime.

The second is the increasing contact between the conflict subjects. The increase of potential subjects deepens the degree of public involvement in conflicts, increases the frequency of contact between citizens and those who implement prevention and control measures, and increases the possibility of conflicts. The conflict subject is not only the direct participant, but also the bystander may become the potential subject of conflict.

Case 3: On the afternoon of February 3, 2020, When five police officers including police Cheng and auxiliary police $\mathrm{Lu}$ drove the police car to pass epidemic prevention station of village, the villagers on duty asked the police car to register. Police Cheng and others told the villagers that they were performing official duties and did not need to register. In the standoff, the villager Wang proposed that the police car can be released only after the light and siren are on. When Cheng and others turned on the police light and siren, a villager Huang with a mobile phone, stood on the side of the police car and took a video while saying "there is an emergency in the village, the police car has sounded the alarm, and the city is listed as a dangerous place." Cheng and others got off the car to control Huang. More than 10 other villagers rushed up to pull and push Cheng and others, causing the villager Huang who was controlled by the police to flee the scene and the coat collars and epaulets of the auxiliary police Lu and Luo were torn.

In this case, in addition to the police Cheng and Huang as direct conflict subjects, other bystanders also participated in the conflict, the scale of the conflict instantly expanded.

Third, the number of non real conflicts is increasing, and the real conflicts can not be adjusted. During the COVID-19 period, the accumulation of citizens' bad emotions is prone to non real conflicts. If there is a conflict between the conflict subjects around the unrealistic goal, the stronger the emotion aroused by the conflict, the more intense the conflict. Because the non realistic conflict takes the conflict itself as the goal. Participating in the conflict is not for the realistic, immediate and realizable interests, but as a form of catharsis of some emotion. The goal of realistic conflict is to achieve a practical and utility purpose, which the clearer is, the more likely the two sides of the conflict will stop the conflict and seek a rational solution. However, during the COVID-19 period, the real goal of the criminal who resists the epidemic prevention and control measures is to cross the epidemic prevention station, which can not be achieved during this period. Therefore, the increase of non real conflicts and the irresolvability of real conflicts also become important parts of the intensification of conflicts during this period.

\subsection{Conflict between Roles-Resistance to Power}

Collins believes that in all stages of human society, almost all people pursue wealth, power and privilege. Everyone in the society tends to resent being directed by others, and everyone tries to avoid being directed by others. Similarly, Foucault also said, "where there is power, there is resistance" [9]. All of them reflect that human beings tend to resist other's power. In modern society, power has various forms, infiltrating into different parts of the society and throughout the whole social body [10]. We cannot escape the danger of power by isolating a pure area or space. Everyone is faced with the problem of how to respond to power in their daily life, working environment and family. Resistance is carried out by the people themselves in their daily social practice, instead of relying on a completely centralized and systematic way. This kind of conflict is the resistance of the weak to those who have a dominant position.

During the period of COVID-19 prevention and control, due to the heavy work tasks, the security of the community, young volunteers and "aunts" in the community are often entrusted with heavy responsibilities. When they undertake part of the tasks of epidemic prevention and control, they have the power to check others, stop passers and so on. During this period, the distribution of power will subvert the daily status, and some people will have a psychological gap, which will intensify the conflict.

Case 4: At about 14:00 on February 4, Wang's four-wheel battery car blocked the entrance and exit channel of the epidemic prevention station. After showing the identity of the epidemic prevention and control staff, Liao and other sasked Wang to cooperate with the epidemic prevention work and move the car away. Wang first said that the battery had no power and could not start a fire. After Liao said he was willing to help push the car, Wang said that Liao and others were not traffic police and had no right to ask them to move the car. Liao and others explained to Wang the requirements of epidemic prevention and control work. Wang felt that Liao and others made such a fuss that there was no need to make it so serious. He pointed at Liao and insulted him for "holding a chicken feather as an arrow". After Liao asked him to cooperate and not curse, Wang became more and more excited. Then Wang punched Liao in the face, causing his facial soft tissue contusion. In order to avoid chaos, Liao and others came forward to stop Wang and hold him down. Wang still kept scratching Liao's face with his hands and scratched out several bloodstains on his face.

Liao asked Wang to move the battery car because of the need of the epidemic. When Liao made it clear that he was willing to help push the car, Wang heaped abuse on Liao and made venomous personal attacks. Moving battery vehicle would not harm the interests of both sides. Wang thought that the order of moving electric vehicle was a "fuss" of Liao, that is, there was no need to exercise power at that time. Wang's action was a rebellion against power and refused to accept Liao's command.

It can also be explained by Dahrendorf's "conflict between roles". The different roles played by different individuals will lead to conflicts because some of them fail to meet the role expectations, leading to "conflicts between roles" [11]. Wang did not move the battery car according to Liao's expectation, and Liao did not give up moving the battery car according to Wang's expectation, resulting in conflicts between the public 
and epidemic prevention and control staff. The conflict between roles is actually the conflict of power between people in different positions. Liao had a dominant position. If Wang wanted to achieve his goal, he could only resist.

\section{Preventive Measures of Crimes of Resisting Epidemic Prevention and Control Measures}

According to the above analysis of social conflict theory on the crime of resisting epidemic prevention and control measures, the following will put forward corresponding countermeasures from three aspects of effective sanctions, feasible communication channels and the strengthening of civic awareness, so as to reduce and prevent the occurrence of such crimes.

\subsection{Effective Sanctions}

Everyone's social role is forced by social rules, and the basic mechanism of its implementation is "sanctions". The reason of conflict between roles is generally to prevent deviant behavior. The use of sanctions can reduce the occurrence of this kind of conflict, and produce a certain deterrent to others. It should be noted that sanctions have negative significance in many cases and play a punitive role. While in some cases, it has a positive meaning and plays a rewarding role.

Although the Opinions was formulated and implemented during the COVID-19 period, the policy of heavier criminal law for the implementation of relevant crimes during the period of epidemic prevention and control was established. However, when combating crimes, we should distinguish the specific circumstances of the crime. Voluntary surrender, Confession and other legal or discretionary circumstances should not be ignored because of its resistance to the epidemic prevention and control measures. Effective sanctions should be implemented so as to punish the offender and form a positive effect.

\subsection{Feasible Communication Channels}

On the one hand, conflict is universal and normal. On the other hand, conflict and interaction are consistent. In the process of interaction, the realization of various daily life rituals is the main mode to solve the conflict. Collins attaches importance to the role of language exchange in the process of conflict. "Generally speaking, all conversation is negotiation." In order to achieve their interests, actors from all walks of life should not only use their power resources, but also try their best to develop their language ability and conduct effective conversation, which help them adjust and coordinate the relationship between "self" and "others". Effective communication can to some extent inhibit the increase of conflict intensity.

In many cases during the COVID-19, there was no peaceful and effective communication between the actors. How to realize feasible communication? First, the implementation of epidemic prevention and control workers in the work, especially when it comes to interaction with the public should try to be patient. The second is to establish a law enforcement evaluation mechanism to transform public communication from offline to online. When the public is dissatisfied with the law enforcement behavior, they can delay the reaction through the village committee, community and street, or they can immediately evaluate it through WeChat group, web page and other ways. If the public is dissatisfied, some bad emotions can be transferred in this way, which can directly reduce face-to-face conflicts and reduce violent crimes against epidemic prevention and control measures.

\subsection{The Strengthening of Civic Awareness}

During the COVID-19 period, citizens were in a closed environment for a long time, which was easy to produce greater personal psychological pressure, anxiety, irritability, negative emotions and so on. We should strengthen education to improve citizens' psychological quality and enhance their sense of social responsibility.

First of all, strengthening the psychological quality education. Using the television, network, media or other public media for psychological counseling education and Opening the public psychological comfort hotline provide a learning platform of basic knowledge of mental health for citizens. Secondly, we should strengthen moral education and legal education. The community can encourage citizens to carry out voluntary anti epidemic activities and participate in the work of anti-epidemic measures in the streets and communities, which is beneficial for citizens and law enforcers to think in another place and reduce conflicts and frictions. Finally, strengthening cultural education. Organizing online community communication activities can be a good way to make up for the decrease of social activities due to the epidemic. Through various ways of education and publicity, enhancing citizens' personal consciousness, strengthening moral education, legal education and cultural education, we can effectively solve the realistic and unrealistic conflicts.

\section{References}

[1] Lewis A. Coser, The Function of Social Conflict, Huaxia publishing house, Beijing, 1989.

[2] Gao Xuanyang, Contemporary Social Theory (Second Edition), China Renmin University Press, Beijing, 2017.

[3] Gao Ye, "Prevention and Control of Female Violent Crime from the Perspective of Social Conflict Theory," Nanchang University, 2019.

[4] Zhang Yuanhuang, Criminology (Third Edition), People's Publishing House of China, Beijing, 2015.

[5] Zhang Yuanhuang, Criminology (Third Edition), People's Publishing House of China, Beijing, 2015.

[6] Jonathan H. Turner, The Structure of Sociological Theory, Zhejiang People's Publishing House, Hangzhou, 1987.

[7] Huang Yifeng, "Analysis of Social Conflict Intensity and Its Influencing Factors", Administrative forum, 2013,20 (03): 37-41.

[8] Lewis A. Coser, Sociological Thinker: Thoughts in Historical and Social Background, China Social Science Press, Beijing, 1990.

[9] Foucault, M., "The History of Sexuality", Vol.1, Allen Lane,1979(1976), p.95.

[10] Foucault, M., "Power-Knowledge: Selected Interviews and Other Writings 1972-1977”, Harvest,1980, p.139. 
[11] Gao Xuanyang. Contemporary Social Theory (Second Edition), China Renmin University Press, Beijing, 2017.

\section{Author Profile}

Rui Zhang received the bachelor degree in law from Zhongnan University of Economics and Law in 2019. She is now studying in the College for Criminal Law Science of Beijing Normal University and will graduate in 2022. Her main research direction is criminal law. 